\title{
Malignant lymphoid polyp - a new category of disease in the large intestine
}

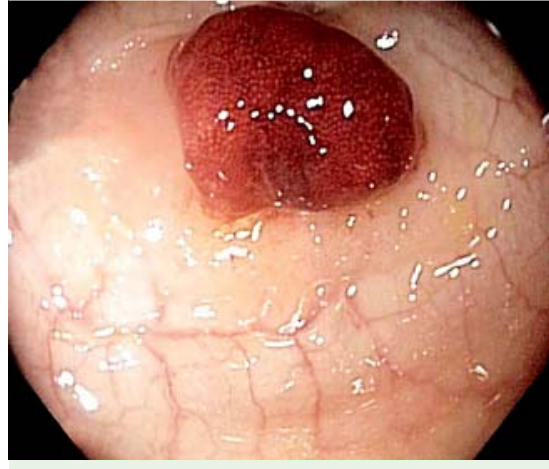

Fig. 1 Isolated reddish polyp with normalappearing overlying mucosa, removed from the sigmoid colon of an asymptomatic 55-yearold man undergoing endoscopic colorectal cancer screening.

The gastrointestinal (GI) tract is a common site of presentation of extranodal lymphomas, although primary GI lymphomas account for only $5 \%$ to $10 \%$ of primary GI neoplasms. The majority of cases occur in the stomach; only approximately $10 \%$ occur in the colorectum. Diffuse large B-cell lymphoma is the most common type of GI tract lymphoma [1].

An asymptomatic 55-year-old man was referred for endoscopic colorectal cancer screening. A reddish polyp, measuring $1 \mathrm{~cm}$ in largest diameter, was removed from the sigmoid colon ( $\bullet$ Fig. 1 ). Histologic examination disclosed closely packed, poorly defined neoplastic follicles with attenuated or absent mantle zones ( $\bullet$ Fig.2a), which were composed of centrocytes and occasional centroblasts ( $\bullet$ Fig. 2b). The neoplastic cells were positive for CD20, BCL2, and CD10 ( Fig.3a, - Fig.3b, 0 Fig. 3c) but lacked expression of CD5, cyclin D1, and CD30. The Ki67 labeling index was less than 10\% ( Fig. 3d). The final diagnosis was follicular lymphoma (grade 1 ). The result of computed tomography was negative for more advanced disease, and the result of a bone marrow biopsy was also normal. Within the GI tract, follicular lymphomas appear mainly as multiple small polyps in the second portion of the duodenum, but they may rarely also be seen in other parts of the GI tract, including the colorectum, often as an incidental finding [1,2]. Only four cases of follicular lymphoma presenting as an isolated colonic polyp have been

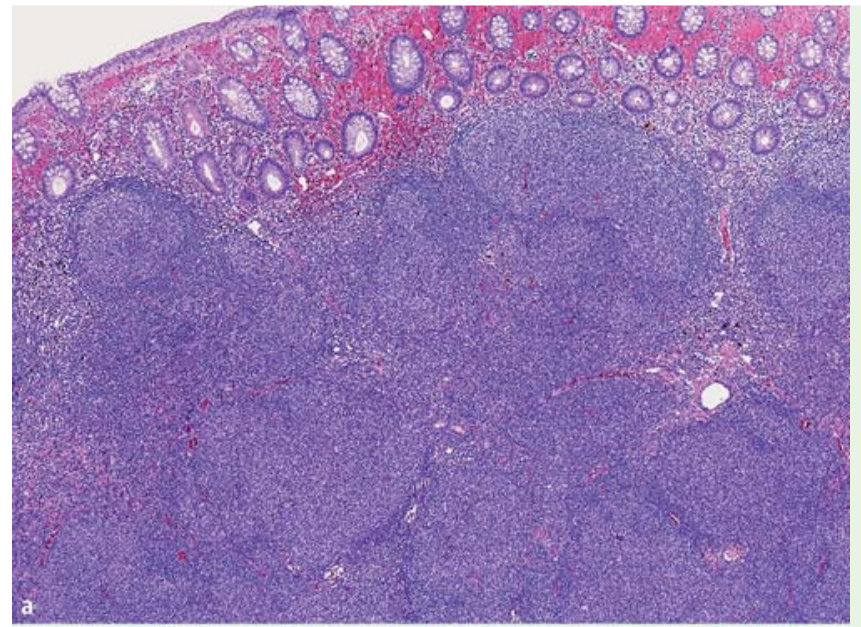

Fig. 2 a Histologic examination shows closely packed, poorly defined neoplastic follicles with attenuated or absent mantle zones (original magnification $\times 40)$. $\mathbf{b}$ These are composed of centrocytes and occasional centroblasts (original magnification $\times 200)$.

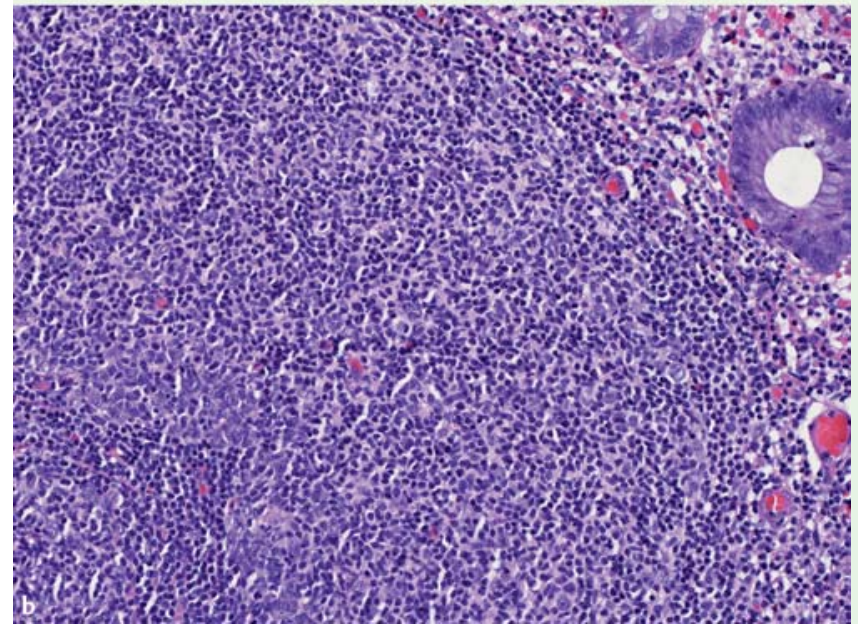

reported [3-6]. The differential diagnosis includes mainly reactive - that is, nonneoplastic - lymphoid hyperplasia or polyp, which is most often observed in the ileum and occasionally the colon. When occurring within the rectum, reactive lymphoid hyperplasia has been referred to as rectal tonsil [7].

Primary malignant GI tract lymphoma presenting as an isolated colonic polyp is exceedingly rare. We suggest the term malignant lymphoid polyp to better categorize this lesion, which may be encountered during screening colonoscopy. Use of the term will improve differentiation of the lesion from reactive lymphoid hyperplasia, which in the GI tract is commonly referred to as benign lymphoid polyp.

\section{Endoscopy_UCTN_Code_CCL_1AD_2AC}

\section{Competing interests: None}

Nicole Max ${ }^{1}$, Franz Siebert ${ }^{2}$, Cord Langner ${ }^{1}$

${ }^{1}$ Institute of Pathology, Medical University of Graz, Graz, Austria

2 Department of Internal Medicine, Krankenhaus der Barmherzigen Brüder, Academic Teaching Hospital,

St. Veit/Glan, Austria

\section{References}

1 O'Malley DP, Goldstein NS, Banks PM. The recognition and classification of lymphoproliferative disorders of the gut. Hum Pathol 2014; 45: 899-916

2 Despott EJ, Tadrous PJ, Naresh KN et al. An unusual finding at screening colonoscopy: polypoid follicular lymphoma with marginal zone differentiation. Endoscopy 2011; 43 (Suppl. 02) UCTN: E266-E267

3 Terada T. Gastrointestinal malignant lymphoma: a pathologic study of 37 cases in a single Japanese institution. Am J Blood Res 2012; 2: $194-200$ 


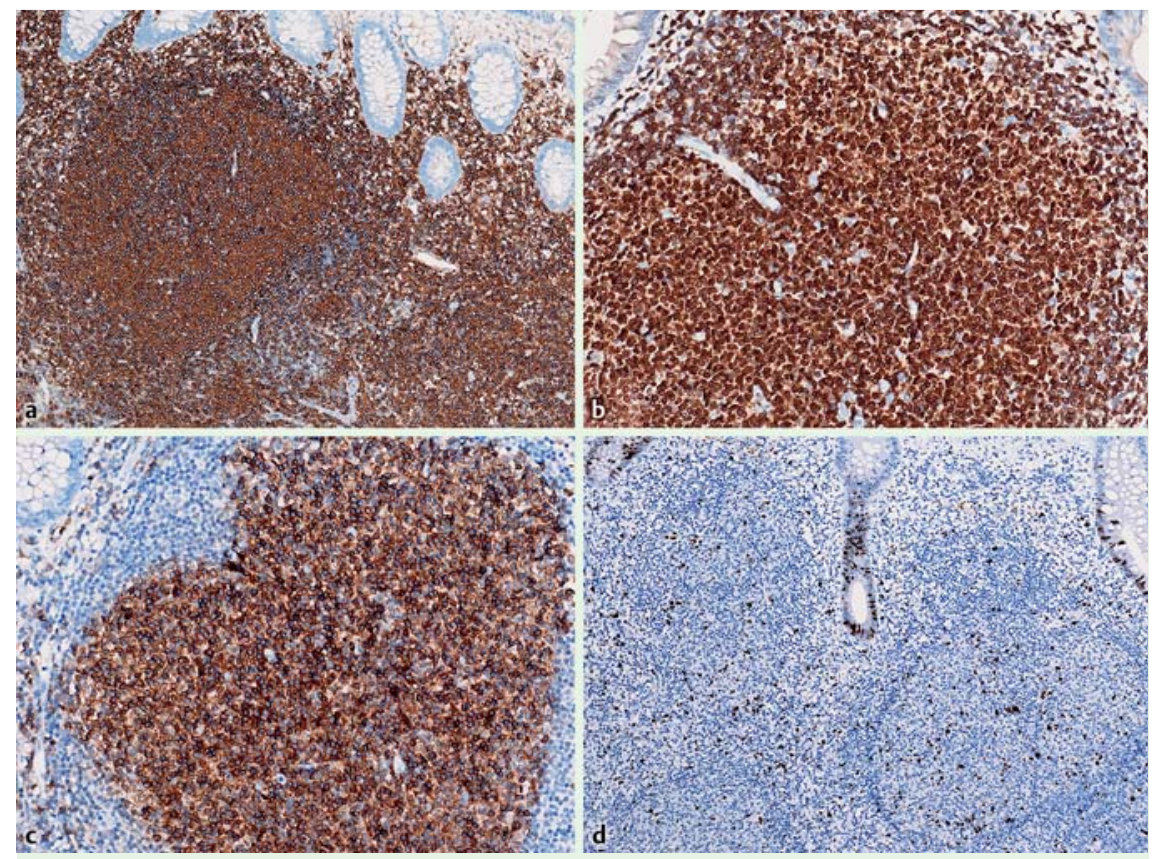

Fig. 3 The neoplastic cells are positive for the following: a CD20 (original magnification $\times 100$ ); $\mathbf{b}$ BCL2 (original magnification $\times 200$ ); c CD10 (original magnification $\times 200$ ). $\mathbf{d}$ The Ki-67 (MIB-1) labeling index is less than $10 \%$ (original magnification $\times 100$ ).
4 Ferreira A, Gonçalves R, Rolanda C. A different kind of colon polyp. Gastroenterology 2012; 143: 1440, 1693-1694

5 Kakati BR, Krishna SG, Dang SM et al. Colonic perforation following polypectomy of a gastrointestinal follicular lymphoma masquerading as a colon polyp. J Gastrointest Cancer 2012; 43: $382-384$

6 Kam JC, Gauchan D, Doraiswamy V et al. Follicular lymphoma presenting as an isolated colonic polyp. J Gastrointest Cancer 2014; 45: $383-386$

7 Farris AB, Lauwers GY, Ferry JA et al. The rectal tonsil: a reactive lymphoid proliferation that may mimic lymphoma. Am J Surg Pathol 2008; 32: 1075-1079

\section{Bibliography}

Dol http://dx.doi.org/

10.1055/s-0034-1393391

Endoscopy 2015; 47: E579-E580

(c) Georg Thieme Verlag KG

Stuttgart · New York

ISSN 0013-726X

\section{Corresponding author \\ Cord Langner, MD}

Institute of Pathology

Medical University of Graz

Auenbruggerplatz 25

A-8036 Graz

Austria

Fax: +43-316 385-13432

cord.langner@medunigraz.at 